\title{
Obstructive Sleep Apnea in Women
}

\author{
Samia Ayub, Christine HJ Won \\ Division of Pulmonary, Critical Care and Sleep Medicine, Yale University School of Medicine, New Haven, CT, USA
}

Received November 26, 2019 Revised December 18, 2019 Accepted December 18, 2019

Address for correspondence Christine HJ Won, MD, MS Section of Pulmonary, Critical Care and Sleep Medicine, Yale University School of Medicine, 300 Cedar St. PO Box 208057, New Haven, CT 06520-8057, USA Tel: +1-203-785-3592 Fax: +1-203-785-3634

E-mail: christine.won@yale.edu
Obstructive sleep apnea is known to be more prevalent in men. In women the prevalence varies throughout her life span as she goes through different stages; puberty, reproductive years, pregnancy and postmenopausal state. The disparity of prevalence within the lifespan of women and in comparison, to men is not only due to different pathophysiologic factors like upper airway anatomy, chemoreflexes, sex hormones but also due to under recognition of sleep disordered breathing in women due to atypical presentation and difference in polysomnographic phenotypes. This review summarizes the literature regarding sleep-disordered breathing in women, its pathophysiology, sex differences in phenotypes and implications of sex differences on management.

J Sleep Med 2019;16(2):75-80

Key Words: Obstructive sleep apnea, Sex differences, Sex characteristics, Sleep apnea syndromes, Sleep-disordered breathing.

\section{Introduction}

Obstructive sleep apnea (OSA) is characterized by repetitive collapse of the upper airway during sleep, often associated with oxygen desaturation and/or arousal from sleep. Prevalence data show that more men than women are affected by OSA even after correcting for age and body mass index (BMI) (Table 1). ${ }^{1-6}$

Sleep apnea tends to be less severe in pre-menopausal women or women receiving hormone replacement treatment compared to untreated post-menopausal women. Likewise, severe OSA [apnea-hypopnea index (AHI) $\geq 30$ ] is more prevalent in middle-aged men and elderly women. ${ }^{7,8}$ Thus, variations in the physiological mechanisms that impact the manifestation of the symptoms linked to sleep disordered breathing (SDB) is likely sex hormone dependent. Sex hormones may lead to differences in the upper airway function and respiratory stability. In addition, women and men may present with disease differently. The limited data available suggest that although the prevalence and severity of OSA may be lower in women, the consequences may be similar or worse, with women suffering greater risk for hypertension and endothelial dysfunction, as well as anxiety and depression. Therefore,

This is an Open Access article distributed under the terms of the Creative Commons Attribution Non-Commercial License (https://creativecommons.org/licenses/by-nc/4.0) which permits unrestricted non-commercial use, distribution, and reproduction in any medium, provided the original work is properly cited. treatment options should be specifically considered in men and women in order to provide best outcomes in women.

\section{Recognition, presenting symptoms, and healthcare utilization}

Factors contributing to sex differences in the prevalence of SDB include variations in the reporting of symptoms in men compared to women. Snoring and excessive daytime sleepiness are considered primary hallmarks of sleep apnea. Our screening tools (e.g. Stop Bang, Epworth Sleepiness Scale) also target these typical symptoms which are reported less frequently by women compared to men experiencing a similar degree of SDB. ${ }^{9}$ Women are more likely to report non-specific symptoms of SDB including headache, fatigue, depression, anxiety, sleep onset insomnia and sleep disruption. ${ }^{3,4} \mathrm{~A}$ population-based sample found that up-to $40 \%$ of women with an AHI >15/h did not report any of the classic OSA symptoms (e.g. snoring, witnessed apneas, and day time sleepiness). ${ }^{7}$ These typical symptoms may be deemed less socially acceptable by females, and as a result are underreported. Atypical symptom presentation results in fewer referrals of women to a sleep clinic, delay in diagnosis, and this leads to increased health care utilization. ${ }^{5,6,10}$ Additional assessment tools, including fatigue, may be necessary to diagnose sleep apnea in women. Hence, we need more comprehensive and specific screening tools for women in general, and likely in different age-groups of women. 
Table 1. Prevalence estimates of moderate to severe OSA in men and women in the general population

\begin{tabular}{|c|c|c|c|c|}
\hline & \multirow{2}{*}{ Age (years) } & \multirow{2}{*}{ Population } & \multicolumn{2}{|c|}{ Moderate-severe OSA (AHI $\geq 15 / \mathrm{hr})$} \\
\hline & & & Males (\%) & Females (\%) \\
\hline Young et al. ${ }^{1}$ & $30-60$ & USA & 9 & 4 \\
\hline Heinzer et al. ${ }^{2}$ & $40-85$ & Switzerland & 50 & 23 \\
\hline Durán et al. ${ }^{3}$ & $30-70$ & Spain & 14 & 7 \\
\hline
\end{tabular}

Different definitions of AHI, and different diagnostic tools were used to define OSA. Please refer to the individual studies for these specifics. OSA: obstructive sleep apnea, AHI: apnea-hypopnea index

\section{Pathophysiology}

\section{Airway anatomy}

There are many factors that contribute to alterations in airway caliber leading to recurrent pharyngeal obstruction during sleep. These include size and stiffness of the pharyngeal lumen, and the pressure gradient across the pharyngeal wall. Differences in properties of the upper airway exist between men and women, and could provide explanation for the dissimilar prevalence. ${ }^{11}$ For example the pharyngeal airway in healthy men is longer compared to women independent of height, and a longer airway tends to collapse more. ${ }^{11,12}$ Similarly in men thickening of the soft tissue on the lateral walls may increase the susceptibility of airway collapse by increasing extraluminal and reducing intraluminal pressure. ${ }^{13,14}$ Sleep apnea is more severe in men compared to women matched for BMI. ${ }^{15}$ Consequently, for a given severity of sleep apnea women tend to be more obese than men. One potential explanation for this difference is the fat distribution between the sexes. For the same BMI, men tend to have higher mean body weight, free fat mass, and neck circumference compared with women. ${ }^{14}$ Upper airway fat distribution in males tends to be particularly in the posterior tongue, which is important in the pathogenesis of OSA. ${ }^{4}$

\section{Ventilatory control and chemo reflex properties}

Alongside anatomical differences, variation in neurochemical control of chest wall and upper airway muscle activity contributes to sex differences in the prevalence of sleepdisordered breathing.

The ventilatory response to changes in chemical stimuli (i.e. hypoxia and hypercapnia) is an integrated response of peripheral and central chemoreflexes. The change in ventilation as a function of the change in the partial pressure of end-tidal carbon dioxide (PETCO2) is a measure of chemoreflex sensitivity (i.e. a steeper slope indicates higher sensitivity). ${ }^{16,17}$ Chemoreflex sensitivity during sleep is often measured by obtaining the slope of the decrease in ventilation that occurs in response to step wise reductions in carbon dioxide (CO2). The chemoreflex threshold, which is typically referred to as the apneic threshold during sleep is the point at which ventilation ceases as a consequence of reductions in PETCO2. ${ }^{18,19}$ The
$\mathrm{CO} 2$ reserve is the difference between baseline levels of PET$\mathrm{CO} 2$ and the PETCO2 at which ventilation is abolished. Low $\mathrm{CO} 2$ reserve promotes breathing instability, because minor increase in ventilation will drop the PETCO2 below the apneic threshold causing apnea. ${ }^{20}$ Hence high chemoreflex sensitivity and decreased $\mathrm{CO} 2$ reserve during sleep will promote apnea. There are sex differences in these parameters contributing to the variability in prevalence of SDB. Zhou et al. showed during sleep chemoreflex sensitivity to $\mathrm{CO} 2$ is greater in men compared to women. ${ }^{21}$ Similar findings were observed in other studies, however during wakefulness, and not sleep. ${ }^{22-31}$ Mixed findings have been reported in terms of sex differences in hypoxic ventilatory response. . $^{24,25,28}$

\section{Respiratory plasticity}

Respiratory plasticity is defined as a persistent change in the neural control system based on prior experience. Plasticity may involve structural and/or functional alterations (most commonly both) and can arise from multiple cellular/synaptic mechanisms at different sites in the respiratory control system. In sleep apnea there is recurrent intermittent hypoxia which initiates at least two forms of respiratory plasticity; progressive augmentation of the hypoxic ventilatory response and long-term facilitation of respiratory motor output (i.e. sustained increase in respiratory motor output (hypoglossal and/ or phrenic) that persists even in normoxic condition) following exposure to intermittent hypoxia. ${ }^{32-36}$ This can contribute to breathing instability during sleep and indeed supports the findings that apnea severity increases from the beginning to end of the night in individuals with sleep apnea. ${ }^{37-41}$ These ventilatory responses to $\mathrm{CO} 2$ after episodic hypoxia are seen to be worse in men compared with women. ${ }^{26}$

\section{Hormones}

It has been reported that women with clinically significant SDB have lower levels of estradiol and/or progesterone when matched for age, menstrual cycle phase or post-menopausal status. ${ }^{42}$ Additionally, the prevalence of sleep apnea in postmenopausal women that do not receive hormone replacement therapy is significantly greater compared to those who receive hormone replacement therapy. ${ }^{43}$ There are conflicting findings on the potential impact that estrogen/progesterone 
has on ventilatory sensitivity to hypercapnia and hypoxia. ${ }^{44-47}$ Rowley et al. supported that estrogen/progesterone decrease the apneic threshold to $\mathrm{CO} 2$ and the sensitivity to hypercapnia or hypoxia, leading to decrease in breathing instability, hence explaining the fact that sleep apnea is less prevalent in menstruating females. ${ }^{44}$

The PETCO2 that demarcates the apneic threshold in premenopausal women is further from baseline compared to that of post-menopausal women. Likewise, treatment with medroxyprogesterone acetate and estrogen leads to increased difference between the apneic threshold and baseline PETCO2 in post-menopausal women (i.e. greater $\mathrm{CO} 2$ reserve).

Female sex hormones also have a protective effect on upper air way patency. This was supported by findings seen in postmenopausal female volunteers that showed activity of the genioglossus muscle significantly increased after 2 weeks of hormone replacement therapy, ${ }^{48}$ potentially explaining the marked increase of prevalence and severity of SDB in women after menopause. $^{43,49,50}$

Pregnancy is associated with an increase in the ventilatory sensitivity to hypoxia and hypercapnia. ${ }^{45-51}$ The increase in sensitivity is due at least in part to the effects of estrogen and progesterone on the carotid body. ${ }^{51}$ Pregnancy is a state of increased risk for OSA despite increased sex hormones since hormonal changes may lead to other risk factors such as a larger neck circumference or naso-oropharyngeal edema. ${ }^{52-56}$ Anatomical changes related to pregnancy also contribute to OSA risk. For example, a growing uterus leads to elevation in the diaphragm with decrease in functional residual capacity.

Finally, increased prevalence of sleep apnea is reported in women with polycystic ovarian syndrome, which is characterized by elevated testosterone levels, compared to reproductively healthy women. Correlation is seen between the AHI and serum testosterone and unbound testosterone in women with polycystic ovarian syndrome. (13,57-59 $^{\text {testo }}$

\section{OSA Phenotypes}

The main metric for capturing SDB has been coined to be the AHI. However, there are likely various phenotypes of SDB with differential impact on clinical outcomes. The AHI is greater in men in non-rapid eye movement (NREM) sleep and particularly in supine position. ${ }^{60}$ In women, AHI is equivalent if not greater in rapid eye movement (REM) sleep, when age and BMI are controlled. ${ }^{61-63}$ Since NREM sleep forms the bulk of the total sleep time, this can contribute to overall increased prevalence of sleep apnea in men compared to women. ${ }^{62,64,65}$ Also many women remain underdiagnosed and under treated if their total AHI is mild or $<15 / \mathrm{hr}$ even though there is greater REM AHI. Given recent data showing adverse cardiovascular outcomes due to REM-OSA (independent of NREM-OSA), ignoring this metric when diagnosing disease or for insurance reimbursement, may result in under-treatment of at-risk women who have greater proclivity for SDB during REM sleep.

Other manifestations of SDB in women that may get ignored as they do not qualify for frank apneas or hypopneas during polysomnography is upper airway resistance syndrome. ${ }^{6-69}$ The underlying characteristic of upper airway resistance syndrome is progressive upper airway narrowing and flow limitation. Sex differences in terms of load responsiveness or central breathing stability may serve to mitigate breathing instability and prevent the development of obstructive or central apnea respectively in women. ${ }^{12,21}$ Hence this upper airway resistance causing high work of breathing and recurrent arousals has been shown to translate into symptoms of non-restorative sleep, daytime fatigue and depression but its effect on other clinical outcomes remain to be studied. ${ }^{70}$

Sleep position has only a small effect on OSA in women, as reflected by the low prevalence of posture-dependent OSA (supine predominant OSA) in women. ${ }^{62}$ Polysomnographic data show that women have shorter apnea events and less severe oxygen desaturations than men. ${ }^{15}$ Another interesting finding is that women are symptomatic at lower AHI cut-off values compared with men with the same AHI. ${ }^{71}$ Females with an AHI of $2-5 / \mathrm{h}$ had a similar level of symptoms to men with an AHI of $\geq 15 / h$. It is possible this may be due to more symptomatic effects of REM sleep disruption. ${ }^{72}$

\section{Clinical Implications}

Clinical trials on consequences of OSA mostly focus on the male population, and only recently have studies looked at female OSA patients. ${ }^{73}$ Greenberg-Dotan et al. found that women with OSA were more likely to have a comorbid condition like cardiovascular disease and diabetes. ${ }^{74}$ Another study showed that women with OSA were more likely to develop dementia and cognitive decline. Correlation was also seen between cognitive decline and increased oxygen desaturation during apneic and hypopneic events in women. ${ }^{75}$ Increased brain white matter changes have been seen in women with OSA compared to male with OSA and is postulated to be responsible for the poor quality of life reported by women. ${ }^{76}$

Overall there is scant data on OSA outcome in female patients, but the available data suggests that long-term consequences of untreated OSA are equal if not worse in women. ${ }^{63}$

\section{Treatment}

Sex differences in treatment response for OSA have not been well studied. The limited data indicate that usage is simi- 
lar between males and females. ${ }^{77,78}$ The positive airway pressure (PAP) requirements however seem to be higher for males than females, after adjusting for baseline OSA severity and BMI. ${ }^{79,80}$ No significant difference has been observed in terms of types of interface used or satisfaction with mask treatment in males and females. ${ }^{81}$ Studies are ongoing to determine the efficacy of PAP devices that have algorithms targeting femalespecific characteristics. A randomized, double-blind, crossover clinical trial found this modality to be as effective as standard continuous PAP. ${ }^{82}$ Non-PAP treatments have rarely been studied in the female-specific population. Weight loss has been seen to be more beneficial for males than females based on the fat distribution in the upper airway of males. ${ }^{83}$ Mandibular advancement devices have been shown to be more successful in females with mild OSA than males likely due to less fat distribution in upper airway in females. ${ }^{84}$ However, more research is needed in these areas to promote personalized therapy.

\section{Conclusion}

As our understanding improves in the area of sex differences in pathophysiology, symptoms presentation and disease manifestation, we need to develop better screening and diagnostic tools for OSA in women, as well as better understand sex-related phenotypes of SDB.

\section{Acknowledgments}

None.

\section{Conflicts of Interest}

The authors have no potential conflicts of interest to disclose.

\section{ORCID iDs}

Samia Ayub https://orcid.org/0000-0002-3358-9355

Christine HJ Won https://orcid.org/0000-0002-8568-8849

\section{Author Contributions}

Christine HJ Won contributed to conceptualization and editing. Samia Ayub contributed to data curation and writing.

\section{REFERENCES}

1. Young T, Palta M, Dempsey J, Skatrud J, Weber S, Badr S. The occurrence of sleep-disordered breathing among middle-aged adults. $N$ Engl J Med 1993;328:1230-1235.

2. Heinzer R, Vat S, Marques-Vidal P, et al. Prevalence of sleep-disordered breathing in the general population: the HypnoLaus study. Lancet Respir Med 2015;3:310-318.

3. Durán J, Esnaola S, Rubio R, Iztueta A. Obstructive sleep apnea-hypopnea and related clinical features in a population-based sample of subjects aged 30 to 70 yr. Am J Respir Crit Care Med 2001;163(3 Pt 1):685689.

4. Shepertycky MR, Banno K, Kryger MH. Differences between men and women in the clinical presentation of patients diagnosed with obstructive sleep apnea syndrome. Sleep 2005;28:309-314.
5. Valipour A, Lothaller H, Rauscher H, Zwick H, Burghuber OC, Lavie P. Gender-related differences in symptoms of patients with suspected breathing disorders in sleep: a clinical population study using the sleep disorders questionnaire. Sleep 2007;30:312-319.

6. Kapur V, Strohl KP, Redline S, Iber C, O’Connor G, Nieto J. Underdiagnosis of sleep apnea syndrome in U.S. communities. Sleep Breath 2002;6:49-54.

7. Bixler EO, Vgontzas AN, Ten Have T, Tyson K, Kales A. Effects of age on sleep apnea in men: I. Prevalence and severity. Am J Respir Crit Care Med 1998;157:144-148.

8. Li Z, Li Y, Yang L, et al. Characterization of obstructive sleep apnea in patients with insomnia across gender and age. Sleep Breath 2015;19: 723-727.

9. Redline S, Kump K, Tishler PV, Browner I, Ferrette V. Gender differences in sleep disordered breathing in a community-based sample. Am J Respir Crit Care Med 1994;149(3 Pt 1):722-726.

10. Banno K, Manfreda J, Walld R, Delaive K, Kryger MH. Healthcare utilization in women with obstructive sleep apnea syndrome 2 years after diagnosis and treatment. Sleep 2006;29:1307-1311.

11. Malhotra A, Huang Y, Fogel RB, et al. The male predisposition to pharyngeal collapse: importance of airway length. Am J Respir Crit Care Med 2002;166:1388-1395.

12. Pillar G, Malhotra A, Fogel R, Beauregard J, Schnall R, White DP. Airway mechanics and ventilation in response to resistive loading during sleep: influence of gender. Am J Respir Crit Care Med 2000;162:16271632.

13. Fogel RB, Malhotra A, Pillar G, Pittman SD, Dunaif A, White DP. Increased prevalence of obstructive sleep apnea syndrome in obese women with polycystic ovary syndrome. J Clin Endocrinol Metab 2001;86:11751180.

14. Whittle AT, Marshall I, Mortimore IL, Wraith PK, Sellar RJ, Douglas NJ. Neck soft tissue and fat distribution: comparison between normal men and women by magnetic resonance imaging. Thorax 1999;54:323328.

15. Ware JC, McBrayer RH, Scott JA. Influence of sex and age on duration and frequency of sleep apnea events. Sleep 2000;23:165-170.

16. Tishler PV, Larkin EK, Schluchter MD, Redline S. Incidence of sleepdisordered breathing in an urban adult population: the relative importance of risk factors in the development of sleep-disordered breathing. JAMA 2003;289:2230-2237.

17. Lin CM, Davidson TM, Ancoli-Israel S. Gender differences in obstructive sleep apnea and treatment implications. Sleep Med Rev 2008; 12:481-496.

18. Mateika JH, Mendello C, Obeid D, Badr MS. Peripheral chemoreflex responsiveness is increased at elevated levels of carbon dioxide after episodic hypoxia in awake humans. J Appl Physiol (1985) 2004;96:11971205.

19. Mateika JH, Omran Q, Rowley JA, Zhou XS, Diamond MP, Badr MS. Treatment with leuprolide acetate decreases the threshold of the ventilatory response to carbon dioxide in healthy males. J Physiol 2004;561: 637-646.

20. Zhang XB, Lin QC, Zeng HQ, Jiang XT, Chen B, Chen X. Erectile dysfunction and sexual hormone levels in men with obstructive sleep apnea: efficacy of continuous positive airway pressure. Arch Sex Behav 2016;45:235-240.

21. Zhou XS, Rowley JA, Demirovic F, Diamond MP, Badr MS. Effect of testosterone on the apneic threshold in women during NREM sleep. J Appl Physiol (1985) 2003;94:101-107.

22. Dempsey JA. Crossing the apnoeic threshold: causes and consequences. Exp Physiol 2005;90:13-24.

23. Zhou XS, Shahabuddin S, Zahn BR, Babcock MA, Badr MS. Effect of gender on the development of hypocapnic apnea/hypopnea during NREM sleep. J Appl Physiol (1985) 2000;89:192-199.

24. Aitken ML, Franklin JL, Pierson DJ, Schoene RB. Influence of body size and gender on control of ventilation. J Appl Physiol (1985) 1986;60: 
1894-1899.

25. Jensen D, Wolfe LA, O'Donnell DE, Davies GA. Chemoreflex control of breathing during wakefulness in healthy men and women. J Appl Physiol (1985) 2005;98:822-828.

26. Morelli C, Badr MS, Mateika JH. Ventilatory responses to carbon dioxide at low and high levels of oxygen are elevated after episodic hypoxia in men compared with women. J Appl Physiol (1985) 2004;97:1673-1680.

27. Patrick JM, Howard A. The influence of age, sex, body size and lung size on the control and pattern of breathing during $\mathrm{CO}_{2}$ inhalation in Caucasians. Respir Physiol 1972;16:337-350.

28. Sebert P, Barthelemy L, Mialon P. $\mathrm{CO}_{2}$ chemoreflex drive of ventilation in man: effects of hyperoxia and sex differences. Respiration 1990; 57:264-267.

29. van Klaveren RJ, Demedts M. Determinants of the hypercapnic and hypoxic response in normal man. Respir Physiol 1998;113:157-165.

30. White DP, Douglas NJ, Pickett CK, Weil JV, Zwillich CW. Sexual influence on the control of breathing. J Appl Physiol (1985) 1983;54:874-879.

31. Tarbichi AG, Rowley JA, Shkoukani MA, Mahadevan K, Badr MS. Lack of gender difference in ventilatory chemoresponsiveness and posthypoxic ventilatory decline. Respir Physiol Neurobiol 2003;137:41-50.

32. Edge D, O'Halloran KD. Chronic intermittent hypoxia blunts the expression of ventilatory long term facilitation in sleeping rats. Adv Exp Med Biol 2015;860:335-342.

33. Rosenzweig I, Williams SC, Morrell MJ. The impact of sleep and hypoxia on the brain: potential mechanisms for the effects of obstructive sleep apnea. Curr Opin Pulm Med 2014;20:565-571.

34. Mateika JH, Narwani G. Intermittent hypoxia and respiratory plasticity in humans and other animals: does exposure to intermittent hypoxia promote or mitigate sleep apnoea? Exp Physiol 2009;94:279-296.

35. Julien C, Bairam A, Joseph V. Chronic intermittent hypoxia reduces ventilatory long-term facilitation and enhances apnea frequency in newborn rats. Am J Physiol Regul Integr Comp Physiol 2008;294:R1356R1366.

36. Mateika JH, Syed Z. Intermittent hypoxia, respiratory plasticity and sleep apnea in humans: present knowledge and future investigations. Respir Physiol Neurobiol 2013;188:289-300.

37. Cala SJ, Sliwinski P, Cosio MG, Kimoff RJ. Effect of topical upper airway anesthesia on apnea duration through the night in obstructive sleep apnea. J Appl Physiol (1985) 1996;81:2618-2626.

38. Charbonneau M, Marin JM, Olha A, Kimoff RJ, Levy RD, Cosio MG. Changes in obstructive sleep apnea characteristics through the night. Chest 1994;106:1695-1701.

39. El-Chami M, Shaheen D, Ivers B, et al. Time of day affects the frequency and duration of breathing events and the critical closing pressure during NREM sleep in participants with sleep apnea. J Appl Physiol (1985) 2015;119:617-626.

40. Fanfulla F, Patruno V, Bruschi C, Rampulla C. Obstructive sleep apnoea syndrome: is the "half-night polysomnography" an adequate method for evaluating sleep profile and respiratory events? Eur Respir J 1997;10:1725-1729.

41. Sforza E, Krieger J, Petiau C. Nocturnal evolution of respiratory effort in obstructive sleep apnoea syndrome: influence on arousal threshold. Eur Respir J 1998;12:1257-1263.

42. Netzer NC, Eliasson AH, Strohl KP. Women with sleep apnea have lower levels of sex hormones. Sleep Breath 2003;7:25-29.

43. Bixler EO, Vgontzas AN, Lin HM, et al. Prevalence of sleep-disordered breathing in women: effects of gender. Am J Respir Crit Care Med 2001; 163:608-613.

44. Rowley JA, Zhou XS, Diamond MP, Badr MS. The determinants of the apnea threshold during NREM sleep in normal subjects. Sleep 2006; 29:95-103.

45. Jensen D, Wolfe LA, Slatkovska L, Webb KA, Davies GA, O’Donnell DE. Effects of human pregnancy on the ventilatory chemoreflex response to carbon dioxide. Am J Physiol Regul Integr Comp Physiol 2005; 288:R1369-R1375.
46. Regensteiner JG, Woodard WD, Hagerman DD, et al. Combined effects of female hormones and metabolic rate on ventilatory drives in women. J Appl Physiol (1985) 1989;66:808-813.

47. Zwillich CW, Natalino MR, Sutton FD, Weil JV. Effects of progesterone on chemosensitivity in normal men. J Lab Clin Med 1978;92:262-269.

48. Popovic RM, White DP. Upper airway muscle activity in normal women: influence of hormonal status. J Appl Physiol (1985) 1998;84:10551062.

49. Young T, Finn L, Austin D, Peterson A. Menopausal status and sleepdisordered breathing in the Wisconsin Sleep Cohort Study. Am J Respir Crit Care Med 2003;167:1181-1185.

50. Dancey DR, Hanly PJ, Soong C, Lee B, Hoffstein V. Impact of menopause on the prevalence and severity of sleep apnea. Chest 2001;120: 151-155.

51. Hannhart B, Pickett CK, Weil JV, Moore LG. Influence of pregnancy on ventilatory and carotid body neural output responsiveness to hypoxia in cats. J Appl Physiol (1985) 1989;67:797-803.

52. Weinberger SE, Weiss ST, Cohen WR, Weiss JW, Johnson TS. Pregnancy and the lung. Am Rev Respir Dis 1980;121:559-581.

53. Izci B, Martin SE, Dundas KC, Liston WA, Calder AA, Douglas NJ. Sleep complaints: snoring and daytime sleepiness in pregnant and preeclamptic women. Sleep Med 2005;6:163-169.

54. Pien GW, Fife D, Pack AI, Nkwuo JE, Schwab RJ. Changes in symptoms of sleep-disordered breathing during pregnancy. Sleep 2005;28: 1299-1305.

55. Mabry RL. Rhinitis of pregnancy. South Med J 1986;79:965-971.

56. Pilkington S, Carli F, Dakin MJ, et al. Increase in Mallampati score during pregnancy. Br J Anaesth 1995;74:638-642.

57. Mokhlesi B, Scoccia B, Mazzone T, Sam S. Risk of obstructive sleep apnea in obese and nonobese women with polycystic ovary syndrome and healthy reproductively normal women. Fertil Steril 2012;97:786-791.

58. Vgontzas AN, Legro RS, Bixler EO, Grayev A, Kales A, Chrousos GP. Polycystic ovary syndrome is associated with obstructive sleep apnea and daytime sleepiness: role of insulin resistance. J Clin Endocrinol Metab 2001;86:517-520.

59. Yang HP, Kang JH, Su HY, Tzeng CR, Liu WM, Huang SY. Apnea-hypopnea index in nonobese women with polycystic ovary syndrome. Int J Gynaecol Obstet 2009;105:226-229.

60. Tashkandi Y, Badr MS, Rowley JA. Determinants of the apnea index in a sleep center population. Sleep Breath 2005;9:181-186.

61. Koo BB, Patel SR, Strohl K, Hoffstein V. Rapid eye movement-related sleep-disordered breathing: influence of age and gender. Chest 2008;134: 1156-1161.

62. O'Connor C, Thornley KS, Hanly PJ. Gender differences in the polysomnographic features of obstructive sleep apnea. Am J Respir Crit Care Med 2000;161:1465-1472.

63. Ye L, Pien GW, Weaver TE. Gender differences in the clinical manifestation of obstructive sleep apnea. Sleep Med 2009;10:1075-1084.

64. Walker RP, Durazo-Arvizu R, Wachter B, Gopalsami C. Preoperative differences between male and female patients with sleep apnea. Laryngoscope 2001;111:1501-1505.

65. Youn M, Kwon JY, Lee KS, Park JH, Lee HW. Gender differences in rapid eye movement-related sleep disordered breathing. Health 2015; 7:106-111.

66. Gold AR, Dipalo F, Gold MS, O'Hearn D. The symptoms and signs of upper airway resistance syndrome: a link to the functional somatic syndromes. Chest 2003;123:87-95.

67. Gold AR, Dipalo F, Gold MS, Broderick J. Inspiratory airflow dynamics during sleep in women with fibromyalgia. Sleep 2004;27:459-466.

68. Guilleminault C, Stoohs R, Kim YD, Chervin R, Black J, Clerk A. Upper airway sleep-disordered breathing in women. Ann Intern Med 1995; 122:493-501.

69. Mohsenin V. Gender differences in the expression of sleep-disordered breathing : role of upper airway dimensions. Chest 2001;120:1442-1447.

70. Guilleminault C, Kirisoglu C, Poyares D, et al. Upper airway resistance 
syndrome: a long-term outcome study. J Psychiatr Res 2006;40:273-279.

71. Young T, Hutton R, Finn L, Badr S, Palta M. The gender bias in sleep apnea diagnosis. Are women missed because they have different symptoms? Arch Intern Med 1996;156:2445-2451.

72. Won CHJ, Reid M, Sofer T, et al. Sex differences in obstructive sleep apnea phenotypes, the multi-ethnic study of atherosclerosis. Sleep 2019 Nov 5 [Epub ahead of print]. https://doi.org/10.1093/sleep/zsz274.

73. Franklin KA, Sahlin C, Stenlund H, Lindberg E. Sleep apnoea is a common occurrence in females. Eur Respir J 2013;41:610-615.

74. Greenberg-Dotan S, Reuveni H, Simon-Tuval T, Oksenberg A, Tarasiuk A. Gender differences in morbidity and health care utilization among adult obstructive sleep apnea patients. Sleep 2007;30:1173-1180.

75. Yaffe K, Laffan AM, Harrison SL, et al. Sleep-disordered breathing, hypoxia, and risk of mild cognitive impairment and dementia in older women. JAMA 2011;306:613-619.

76. Macey PM, Kumar R, Yan-Go FL, Woo MA, Harper RM. Sex differences in white matter alterations accompanying obstructive sleep apnea. Sleep 2012;35:1603-1613.

77. Woehrle H, Graml A, Weinreich G. Age- and gender-dependent adherence with continuous positive airway pressure therapy. Sleep Med 2011;12:1034-1036.

78. Campos-Rodriguez F, Martinez-Garcia MA, Reyes-Nuñez N, et al.
Long-term continuous positive airway pressure compliance in females with obstructive sleep apnoea. Eur Respir J 2013;42:1255-1262.

79. Jayaraman G, Majid H, Surani S, Kao C, Subramanian S. Influence of gender on continuous positive airway pressure requirements in patients with obstructive sleep apnea syndrome. Sleep Breath 2011;15:781-784.

80. Yukawa K, Inoue Y, Yagyu H, et al. Gender differences in the clinical characteristics among Japanese patients with obstructive sleep apnea syndrome. Chest 2009;135:337-343.

81. Bachour A, Vitikainen P, Virkkula P, Maasilta P. CPAP interface: satisfaction and side effects. Sleep Breath 2013;17:667-672.

82. McArdle N, King S, Shepherd K, et al. Study of a novel APAP algorithm for the treatment of obstructive sleep apnea in women. Sleep 2015; 38:1775-1781.

83. Newman AB, Foster G, Givelber R, Nieto FJ, Redline S, Young T. Progression and regression of sleep-disordered breathing with changes in weight: the Sleep Heart Health Study. Arch Intern Med 2005;165:24082413.

84. Marklund M, Stenlund H, Franklin KA. Mandibular advancement devices in 630 men and women with obstructive sleep apnea and snoring: tolerability and predictors of treatment success. Chest 2004;125:12701278. 